\title{
Studies towards optimising the isolation of diplonine, a neurotoxin isolated from cultures of Stenocarpella maydis (Berk.) Sacc.
}

\author{
Authors: \\ Leendert D. Snyman ${ }^{1}$ \\ Bradley C. Flett ${ }^{2,3}$ \\ Rowina A. Schultz ${ }^{1}$

\section{Affiliations:} \\ ${ }^{1}$ Department of Toxicology, \\ Agricultural Research \\ Council, Onderstepoort \\ Veterinary Institute, \\ South Africa \\ ${ }^{2}$ Crop Protection (Pathology), \\ Agricultural Research \\ Council, Grain Crop Institute, \\ Potchefstroom, South Africa \\ ${ }^{3}$ Unit of Environmental \\ Sciences and Development, \\ North-West University, \\ Potchefstroom Campus, \\ South Africa
}

\section{Correspondence to:} Leendert Snyman

Email:

snyman@oranet.co.za

Postal address:

Private Bag X05

Onderstepoort 0110, South

Africa

Dates:

Received: 30 Jan. 2014 Accepted: 07 Apr. 2014 Published: 12 Nov. 2014

How to cite this article: Snyman, L.D., Flett, B.C. \& Schultz, R.A., 2014, 'Studies towards optimising the isolation of diplonine, a neurotoxin isolated from cultures of Stenocarpella maydis (Berk.) Sacc.', Onderstepoort Journal of Veterinary Research 81(1), Art. \#765, 4 pages. http://dx.doi.org/10.4102/ ojvr.v81i1.765

Read online:
Diplonine, a mycotoxin that induces neurotoxic clinical signs in the guinea pig, resembling those occurring in cattle and sheep with diplodiosis, was isolated previously from a Stenocarpella maydis culture. Knowledge of the chemical properties of the toxin, which was characterised as a substituted ß-cyclopropylamino acid, enabled amendments in the present study to the initial steps of the isolation procedure. Extraction with water and fractionation by cation exchange chromatography improved the efficiency of isolation, potentially allowing the preparation of larger amounts of the toxin.

\section{Communication}

A toxin designated diplonine (Figure 1), which induced neurotoxic clinical signs in the guinea pig resembling diplodiosis in cattle and sheep (Kellerman et al. 2005), was recently isolated from cultures of Stenocarpella maydis (Snyman et al. 2011). The isolate was cultured using the technique of Flett and McLaren (1994). It was suggested that diplonine, characterised as a substituted ß-cyclopropylamino acid, might be the neurotoxin responsible for diplodiosis in cattle and sheep. To prove this hypothesis large amounts of diplonine are required. The method whereby diplonine is isolated (Figure 2), however, yields only minute amounts of the toxin ( $21 \mathrm{mg}$ from $1200 \mathrm{~g}$ culture). Improvement of this method, based on knowledge of the chemical properties of diplonine, was therefore investigated in an attempt to prepare sufficient amounts of the toxin. Specifically, extraction with water and subsequent fractionation by cation exchange chromatography were investigated. In addition, photographs of the neurotoxic clinical signs induced in a guinea pig dosed with diplonine in a previous study (Snyman et al. 2011) are presented. The clinical trials were performed in accordance with the South African National Standard (The care and use of animals for scientific purposes [SANS 10386:200X]). Animal experiments were approved by the Agricultural Research Council - Onderstepoort Veterinary Institute (ARC-OVI) Animal Ethics Committee.

\section{Extraction with water}

As laboratory observations indicated that diplonine might be more soluble in water than in methanol, extraction of the neurotoxin with water was investigated. The same $S$. maydis culture used by Schultz et al. (2011) (Experiment 1) was used in this study. This culture was isolated from a S. maydis-infected maize kernel, onto potato dextrose agar (PDA) (Flett \& McLaren 1994) and maintained as a culture on a PDA slant in the Agricultural Research Council - Grain Crops Institute (ARC-GCI) collection. Schultz et al. (2011) found a methanolic extract of this culture to be severely to extremely toxic using a guinea pig bio-assay, with typical paretic signs as a guide after being dosed via a stomach tube (Table 1). Bio-assays in this study were similarly performed. In the present study, culture material $(100 \mathrm{~g})$ was extracted with $250 \mathrm{~mL}$ water (saturated with chloroform) for $24 \mathrm{~h}$ on a mechanical shaker (Labotec SP4; Labotec, Midrand, South Africa). The extract was centrifuged in an Allegro X-22R centrifuge (Beckmann Coulter Inc., Johannesburg, South Africa) at $4500 \mathrm{rpm}$ for $40 \mathrm{~min}$. The supernatant was decanted and the pellet stirred up with a volume of water equal to the decanted supernatant. After being centrifuged under the same conditions the supernatants were combined and defatted twice by extraction with equal volumes of hexane (Merck AR; Merck [Pty] Ltd, Johannesburg, South Africa). Bio-assaying of the dried extract at a dose equivalent to $101 \mathrm{~g}$ culture $/ \mathrm{kg}$ body weight (BW) resulted in moderate neurotoxic signs in a guinea pig, whilst a dose equivalent to $174 \mathrm{~g}$ culture $/ \mathrm{kg}$ BW proved to be fatally toxic as it resulted in mortality of the guinea pig $6 \mathrm{~h}$ after being dosed. A dose equivalent to $62 \mathrm{~g}$ culture $/ \mathrm{kg}$ BW did not elicit neurological signs in a guinea pig. A comparison of these dosing rates with that of the methanol extracts (Table 1) indicated a much higher yield of the neurotoxin when extracted with water.

Copyright: (C) 2014. The Authors. Licensee: AOSIS OpenJournals. This work is licensed under the Creative Commons Attribution License. 


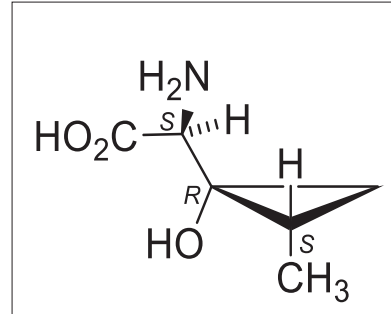

(1)

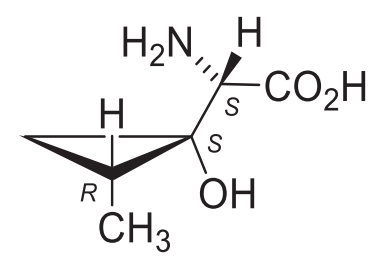

(2)

Source: Snyman, L.D., Kellerman, T.S., Vleggaar, R., Flett, B.C., Basson, K.M. \& Schultz, R.A., 2011, 'Diplonine, a neurotoxin isolated from cultures of the fungus Stenocarpella maydis (Berk.) Sacc. that induces diplodiosis', Journal of Agricultural and Food Chemistry 59, 9039-9044. http://dx.doi.org/10.1021/jf202735e

FIGURE 1: The chemical structures of diplonine (1 or 2 ).

Frenocarpella maydis culture
Fextraction with methanol
(1) chloroform : methanol : ammonia (40:60:0.8)
Residue of toxic fraction
Residue of methanol phase
Fractionation on RP18 by gradient elution with:
Acetonitrile and water ( $0.1 \%$ acetic acid)

Source: Snyman, L.D., Kellerman, T.S., Vleggaar, R., Flett, B.C., Basson, K.M. \& Schultz, R.A., 2011, 'Diplonine, a neurotoxin isolated from cultures of the fungus Stenocarpella maydis (Berk.) Sacc. that induces diplodiosis', Journal of Agricultural and Food Chemistry 59, 90399044. http://dx.doi.org/10.1021/jf202735e

FIGURE 2: Schematic representation of the original isolation of diplonine.

\section{Fractionation by cation exchange chromatography}

As diplonine is an amino acid derivative, purification of the water extract by ion exchange chromatography seemed to be a logical first step in the chromatographic purification of diplonine. By using cation exchange chromatography, all non-ionic and negatively charged substances at a $\mathrm{pH}$ of 3.5 could be eliminated in one step, including arabitol, which severely hampered the purification of diplonine (unpublished observations) in the previous study (Snyman et al. 2011). Fractionation of the water extract by means of cation exchange chromatography was performed with precooled liquids $\left( \pm 5^{\circ} \mathrm{C}\right)$ as follows: the $\mathrm{pH}$ of an amount of the water extract $(84 \mathrm{~mL})$ equivalent to $40 \mathrm{~g} S$. maydis culture was adjusted to $\mathrm{pH} 3.5$ by addition of glacial acetic acid (Merck AR; Merck [Pty] Ltd, Johannesburg, South Africa). The extract was passed through $70 \mathrm{~g}$ Amberlite IR-120 H cation exchange resin (BDH; MCL [Pty] Ltd, Johannesburg, South Africa), packed in a $55 \mathrm{~mm}$ diameter glass column, at a rate of $1 \mathrm{drop} / \mathrm{s}$. The resin was then washed with $300 \mathrm{~mL}$ water followed by elution with $200 \mathrm{~mL} 1 \mathrm{M}$ ammonium hydroxide (Merck AR; Merck [Pty] Ltd, Johannesburg, South Africa).

The dried eluate $(325 \mathrm{mg}$ ) elicited moderate signs of neurotoxicity when dosed to a $155 \mathrm{~g}$ guinea pig (equivalent to $258 \mathrm{~g}$ culture $/ \mathrm{kg} \mathrm{BW}$ ). A replicate yielded $298 \mathrm{mg}$ of the dried eluate and induced mild neurological signs when dosed to a $145 \mathrm{~g}$ guinea pig (equivalent to $275 \mathrm{~g}$ culture $/ \mathrm{kg} \mathrm{BW}$ ). Comparison of these dosing rates (culture equivalents) with that of the water extracts (Table 1) indicated a marked loss of toxicity during cation exchange chromatography. When comparing the dosing rates ( $\mathrm{mg}$ dried residue $/ \mathrm{kg} \mathrm{BW}$ ) of the eluates from the cation exchange column with that of pure diplonine (Table 1), it was evident that although considerable purification had been achieved by cation exchange chromatography, impurities were still present. In contrast to the water extract, only $30 \%$ of pure diplonine $(20 \mathrm{mg})$ was lost when passing it through the column, which might indicate suboptimal chromatographic conditions when fractionating the extract. The dosing rate ( $\mathrm{mg}$ dried residue $/ \mathrm{kg} \mathrm{BW}$ ) of the ammonia eluate nevertheless compares favourably with that of the toxic fraction obtained after two fractionations on silica gel with the chloroform : methanol : ammonia mobile phase (3353 mg/ $\mathrm{kg} \mathrm{BW)} \mathrm{in} \mathrm{the} \mathrm{original} \mathrm{isolation} \mathrm{of} \mathrm{diplonine}$ (Snyman et al. 2011). The published method was more expensive, took longer and was more laborious to perform. The amended procedure shows potential for large-scale preparation of diplonine, especially if the loss of toxicity during cation exchange chromatography can be reduced by further optimisation of the chromatographic conditions.

\section{Neurotoxic clinical signs in a guinea pig}

The neurological signs induced in the guinea pigs by the various fractions largely corresponded with those of

TABLE 1: Toxicity of various fractions as reflected by the severity of neurotoxic signs in a guinea pig.

\begin{tabular}{|c|c|c|c|}
\hline \multirow[t]{2}{*}{ Fraction bio-assayed } & \multicolumn{2}{|c|}{ Dosing Rate } & \multirow[t]{2}{*}{ Severity of neurotoxic signs } \\
\hline & $\begin{array}{c}\text { Culture equivalent } \\
\text { (g/kg BW) }\end{array}$ & $\begin{array}{c}\text { Dried residue } \\
(\mathrm{mg} / \mathrm{kg} \mathrm{BW})\end{array}$ & \\
\hline Methanol extract (Schultz et al. 2011) & $474-535(n=10)$ & - & Severe to extreme \\
\hline Water extract & $\begin{array}{c}62 \\
101 \\
174\end{array}$ & $\begin{array}{l}- \\
-\end{array}$ & $\begin{array}{l}\text { Unaffected } \\
\text { Moderate } \\
\text { Fatal }\end{array}$ \\
\hline Ammonia eluate collected from cation exchange columns & $\begin{array}{l}258 \\
275\end{array}$ & $\begin{array}{l}2096 \\
2055\end{array}$ & $\begin{array}{l}\text { Moderate } \\
\text { Mild }\end{array}$ \\
\hline
\end{tabular}

Source: Findings as per this study; for more information on the methanol and diplonine dosing rates, see the reference list for the article: Snyman, L.D., Flett, B.C. \& Schultz, R.A., 2014, 'Studies towards optimising the isolation of diplonine, a neurotoxin isolated from cultures of Stenocarpella maydis (Berk.) Sacc.', Onderstepoort Journal of Veterinary Research 81(1), Art. \#765, 4 pages. http://dx.doi.org/10.4102/ojvr.v81i1.765

$\dagger$, mild, paresis in the hindquarters; moderate, frequent falling; severe, lateral recumbency; extreme, paralysis. 
the pure toxin, diplonine. The clinical signs elicited by diplonine had previously only been described (Snyman et al. 2011) but not photographically documented. For this reason, a series of photographs (Figures 3-7) showing progression of intoxication in the guinea pig dosed with diplonine have been included. The photographs corroborate the resemblance to clinical signs in cattle and sheep, and thereby the suggestion that diplonine might be the neurotoxin responsible for diplodiosis in cattle and sheep (Snyman et al. 2011). Additionally, this photographic record may serve as an important reference for further studies on diplodiosis when guinea pigs are used as a model.

In conclusion, the procedures investigated seem to be promising in producing the higher quantities of diplonine required to prove that diplonine is the neurotoxin that causes diplodiosis in cattle and sheep. This has, to some extent, already been demonstrated by the neurotoxic clinical signs that were induced in a guinea pig, as photographically illustrated in this article.

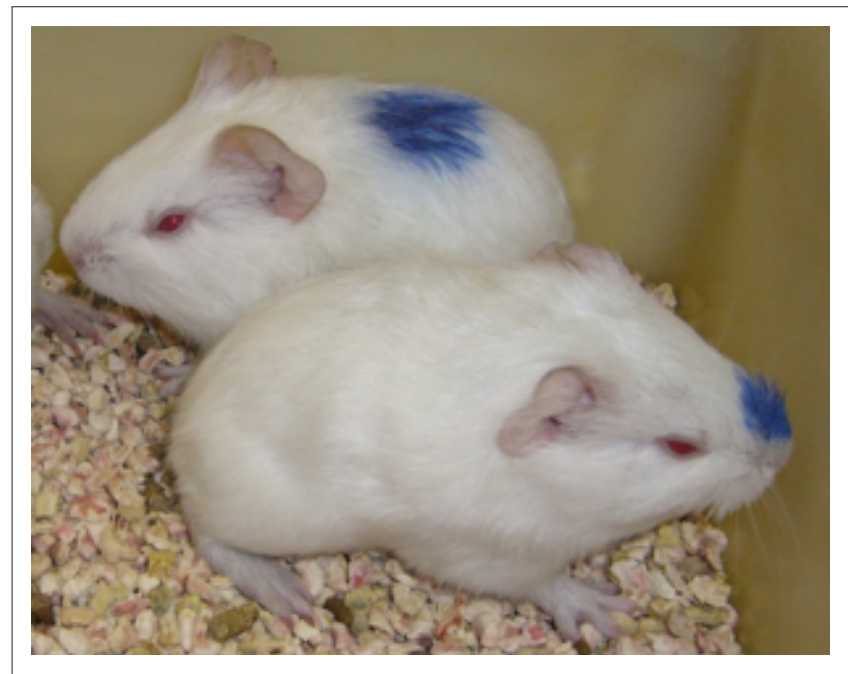

Source: Photographed by R.A. Schultz

FIGURE 3: Guinea pig (in front) immediately after dosing with diplonine, showing no clinical signs (normal).

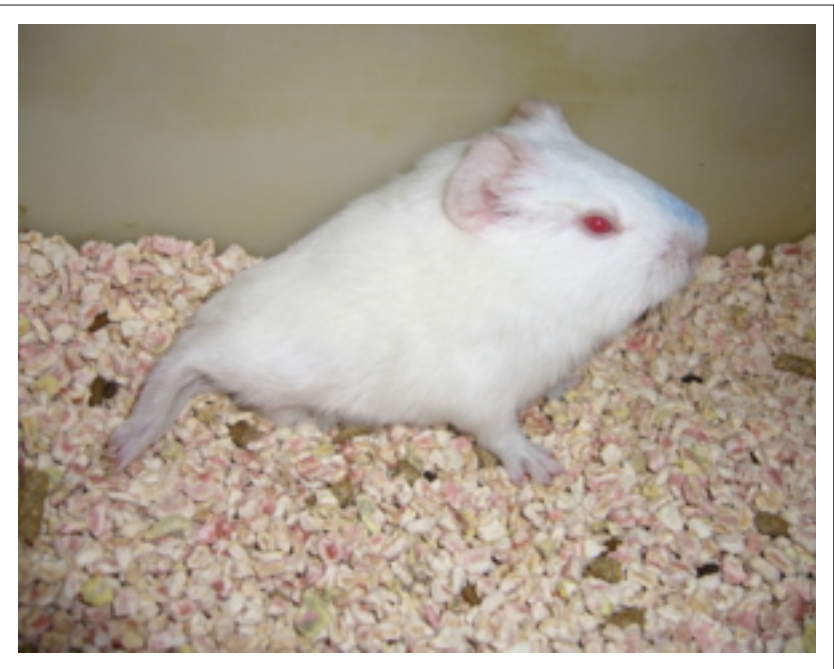

Source: Photographed by R.A. Schultz

FIGURE 4: Guinea pig $12 \mathrm{~h}$ after dosing with diplonine, showing paresis in the hindquarters (mildly affected).

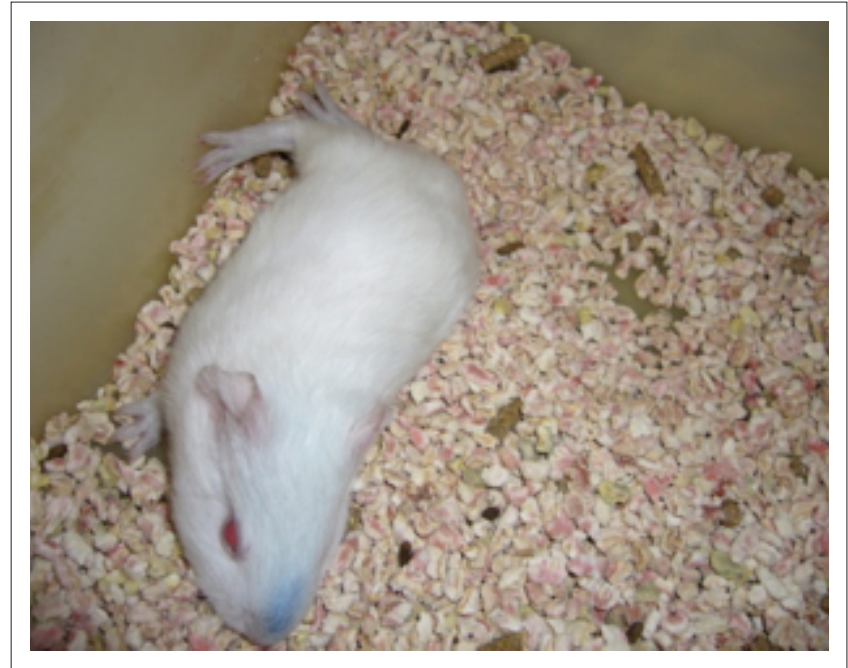

Source: Photographed by R.A. Schultz

FIGURE 5: Guinea pig $24 \mathrm{~h}$ after dosing with diplonine, experiencing frequent falling (moderately affected).

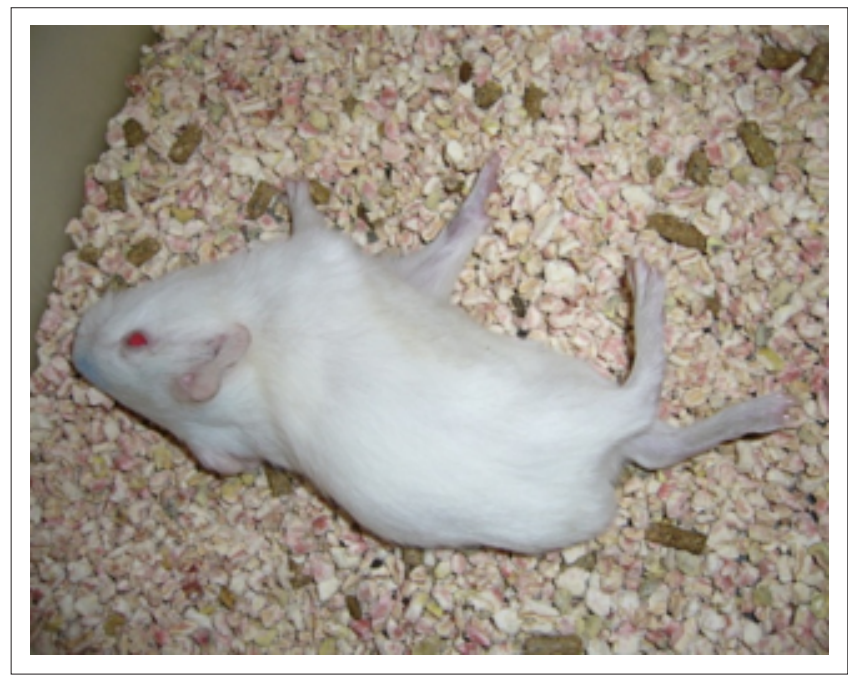

Source: Photographed by R.A. Schultz

FIGURE 6: Guinea pig $36 \mathrm{~h}$ after dosing with diplonine, exhibiting lateral recumbency (severely affected).

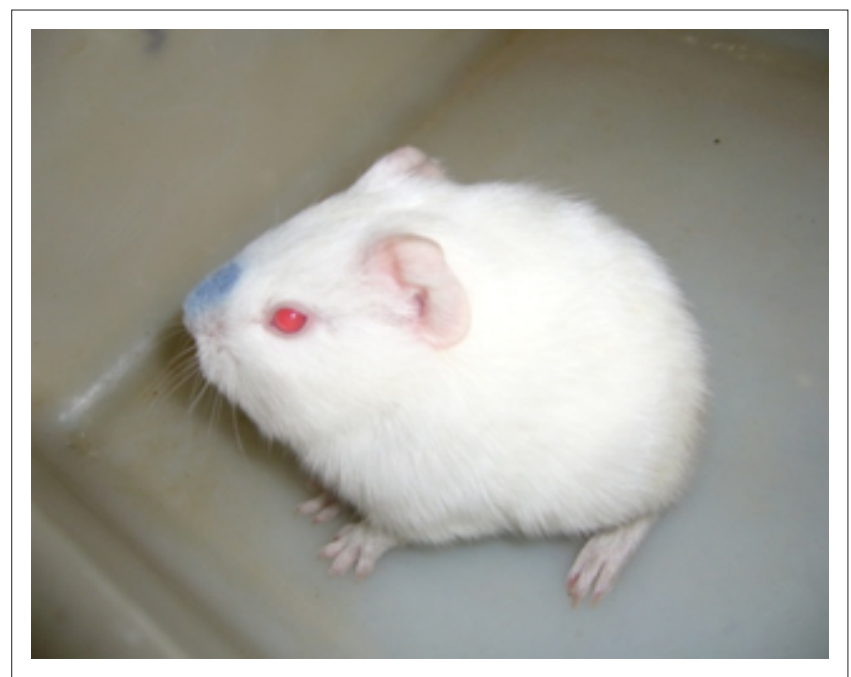

Source: Photographed by R.A. Schultz

FIGURE 7: Guinea pig $48 \mathrm{~h}$ after dosing with diplonine, showing no clinical signs apart from righting reflexes (recovered). 


\section{Acknowledgements}

The Maize Trust is gratefully acknowledged for funding this research.

\section{Competing interests}

The authors declare that they have no financial or personal relationships which may have inappropriately influenced them in writing this article.

\section{Authors' contributions}

B.C.F. (ARC-GCI) was responsible for the S. maydis cultures. L.D.S. (ARC-OVI) performed the extraction and compiled the manuscript. R.A.S. (ARC-OVI) was responsible for the clinical trials.

\section{References}

Flett, B.C. \& McLaren, N.W., 1994, 'Optimum disease potential for evaluating resistance to Stenocarpella maydis ear rot in corn hybrids', Plant Diseases 78 , 587-589. http://dx.doi.org/10.1094/PD-78-0587

Kellerman, T.S., Coetzer, J.A.W., Naudé, T.W. \& Botha, C.J., 2005, Plant poisonings and mycotoxicoses of livestock in southern Africa, 2nd edn., Oxford University Press, Cape Town.

Schultz, R.A., Snyman L.D., Basson, K.M. \& Labuschagne, L., 2011, 'The use of a guinea pig model in detecting diplodiosis, a neuromycotoxicosis of ruminants' in F. Riet-Correa, J. Pfister, A.L. Schild \& T. Wierenga (eds.), Poisoning by plants, mycotoxins and related toxins: 8th International Symposium on Poisonous Plants, UK proceedings, João Pessoa-Paraiba, Brazil, 04-08 May 2009, pp. 520523, CABI, Wallingford.

Snyman, L.D., Kellerman, T.S., Vleggaar, R., Flett, B.C., Basson, K.M. \& Schultz, R.A., 2011, 'Diplonine, a neurotoxin isolated from cultures of the fungus Stenocarpella maydis (Berk.) Sacc. that induces diplodiosis', Journal of Agricultural and Foo 